OPEN ACCESS

Edited by:

Linsheng Song,

Dalian Ocean University, China

Reviewed by:

Ikuo Hirono,

Tokyo University of Marine Science and Technology, Japan

Shengkang Li,

Shantou University, China

Anchalee Tassanakajon,

Chulalongkorn University, Thailand

*Correspondence: Xiaoqian Tang tangxq@ouc.edu.cn

Specialty section:

This article was submitted to Comparative Immunology, a section of the journal

Frontiers in Immunology

Received: 14 August 2020 Accepted: 05 November 2020 Published: 07 December 2020

Citation:

Cui C, Liang $Q$, Tang $X$, Xing J, Sheng $X$ and Zhan $W$ (2020) Differential Apoptotic Responses of Hemocyte Subpopulations to White Spot Syndrome Virus Infection in Fenneropenaeus chinensis.

Front. Immunol. 11:594390. doi: 10.3389/fimmu.2020.594390

\section{Differential Apoptotic Responses of Hemocyte Subpopulations to White Spot Syndrome Virus Infection in Fenneropenaeus chinensis}

\author{
Chuang Cui ${ }^{1}$, Qianrong Liang ${ }^{1}$, Xiaoqian Tang ${ }^{1,2^{*}}$, Jing Xing ${ }^{1,2}$, Xiuzhen Sheng ${ }^{1}$ \\ and Wenbin Zhan ${ }^{1,2}$ \\ 1 Laboratory of Pathology and Immunology of Aquatic Animals, KLMME, Ocean University of China, Qingdao, China, \\ ${ }^{2}$ Laboratory for Marine Fisheries Science and Food Production Processes, Qingdao National Laboratory for Marine \\ Science and Technology, Qingdao, China
}

The apoptosis of hemocytes plays an essential function in shrimp immune defense against pathogen invasions. In order to further elucidate the differential apoptotic responses of the granulocytes and the hyalinocytes in Fenneropenaeus chinensis post WSSV infection, the characteristics of apoptotic dynamics and viral proliferation in total hemocytes and hemocyte subpopulations were respectively investigated in the present work. The results showed that the apoptotic rate of hemocytes changed significantly, and the apoptosis-related genes also showed significantly differential expression responses during WSSV infection. Interestingly, we found that the apoptotic rate of virus-negative hemocytes was significantly higher than that of virus-positive hemocytes in the early stage of WSSV infection, while it was significantly lower than that of virus-positive cells in the middle and late infection stages. The difference of apoptosis between virus-positive and virus-negative hemocytes seems to be an important way for the WSSV to destroy the host's immune system and facilitate the virus spread at different infection stages. It was further found that the apoptosis rate of granulocytes was always significantly higher than that of hyalinocytes during WSSV infection, indicating that granulocytes have a stronger apoptotic response to WSSV infection. Moreover, a higher viral load was detected in granulocytes, and the density of granulocytes decreased more rapidly post WSSV infection, indicating that the granulocytes are more susceptible and vulnerable to WSSV infection compared with the hyalinocytes. These results collectively demonstrated that the apoptotic response in shrimp hemocytes was significantly influenced by the WSSV infection, and the differential apoptotic response of granulocytes and hyalinocytes to WSSV indicated the differences of antiviral mechanisms between the two hemocyte subpopulations.

Keywords: apoptosis, hemocyte subpopulations, Fenneropenaeus chinensis, white spot syndrome virus, hemocytes 


\section{INTRODUCTION}

As invertebrates, shrimp lack the acquired immunity and depend on the inherent immune system to combat pathogen invasion (1, 2). Hemocyte is one of the main immune cells in shrimp, which plays crucial roles both in humoral and cellular immunity. Hemocytes participate in the humoral immunity process by synthesizing and releasing immune molecules such as antibacterial peptides, lectins, and crustin (3-5). Hemocytes are involved in the cellular immunity process mainly through phagocytosis, apoptosis, encapsulation and nodule formation $(6,7)$. Based on their stainability and morphological features, hemocytes of shrimp are generally divided into granulocytes, semi-granulocytes and hyalinocytes $(1,8)$. Some researchers separated the three types of hemocyte subpopulations through flow cytometry or Percoll gradient centrifugation, which exhibited different expression profiles of immune-related genes $(9,10)$. However, we found that it is extremely difficult to sort out high-purity hemocyte subpopulations of Fenneropenaeus chinensis by these two methods. Fortunately, the granulocytes (containing semi-granulocytes) and the hyalinocytes with purities of up to $95 \%$ were successfully separated in our previous studies by immunomagnetic bead combined with monoclonal antibodies that could specifically recognize granule-containing hemocytes (including semi-granulocytes and granulocytes) of $F$. chinensis, and the differential protein expression profiles between the two subpopulations were further explored (11-13). It was also reported that the hyalinocytes participate in the immune response mainly through phagocytosis, while the granule-containing hemocytes resist pathogens by storing and releasing immune factors, such as pro-phenoloxidase (proPO), AMPs, and others (14-16). These evidences demonstrated that those differences of the hemocyte subpopulations are the functional basis for shrimp in response to pathogen invasion.

Apoptosis, a kind of programmed cell death, plays vital roles in a variety of biological processes and diseases $(17,18)$. It is generally considered that apoptosis serves as a kind of innate immune pathway conserved in shrimp, involving in the antiviral process (19). When the pathogen invades the host cells, the cells initiate apoptosis to hamper the pathogen proliferation and spread (19-21). However, some pathogens have evolved diverse strategies to inhibit apoptosis, thereby providing favorable conditions for self-proliferation $(22,23)$. When the pathogen completed proliferation, the intentionally induced apoptosis would facilitate the release of pathogen progeny (24, 25). White spot syndrome virus (WSSV), a large enveloped DNA virus, could infect most shrimp species and has caused huge economic losses in the shrimp culture industry $(26,27)$. Previous studies have confirmed that WSSV infection induced apoptosis of major tissues cells in shrimp (28). Over the years, it has been proven that some apoptosis-related genes in shrimp could inhibit or promote WSSV proliferation $(29,30)$. Conversely, some WSSV envelope proteins could also modulate the host cell apoptosis during infection, thereby facilitating viral replication and expansion (31-34). In our previous studies, it was also found that the hemocytes apoptosis process in Litopenaeus vannamei fluctuated significantly during WSSV infection (35). These evidences suggested that the WSSV infection is closely related to the apoptotic process. Meanwhile, WSSV appears to exhibit different proliferation dynamics in different hemocyte subpopulations $(36,37)$. And WSSV infection also caused the differential protein expressions between the granulocytes and hyalinocytes of shrimp (13). These reports indicated that there are differences in immune responses among the hemocyte subpopulations during WSSV infection. However, there have been no studies on the differential apoptotic responses of hemocyte subpopulations to WSSV infection and the differences of viral infection characteristics between hemocyte subpopulations.

In order to provide the thorough comprehension of relationship between the apoptotic dynamics of hemocytes and the WSSV infection process, the TUNEL assay and real-time qPCR were utilized to detect the characteristics of hemocytes apoptosis in F. chinensis during WSSV infection. Meanwhile, the WSSV infection process in hemocytes and the accumulative mortality of WSSV-infected shrimp were also investigated. Moreover, the laboratory-prepared monoclonal antibodies combined with the TUNEL assay and immunomagnetic bead method were used to further study the differential apoptotic responses and the differences of WSSV-infection process between granulocytes and hyalinocytes during WSSV infection, which would provide more information on the functional differences of the hemocyte subpopulations.

\section{MATERIALS AND METHODS}

\section{Shrimp and WSSV Infection}

The healthy shrimp ( $F$. chinensis, $15-18 \mathrm{~cm}$ ) were obtained in a Qingdao Harbor, Shandong province, China. Five shrimp were randomly selected for testing WSSV to ensure that the shrimp were WSSV-free according to the method described previously (38). The shrimp were kept in aerated seawater at $24^{\circ} \mathrm{C}$ for about a week before the experiment. This study was carried out in agreement with the International Guiding Principles for Biomedical Research Involving Animals documented by Guide for the Use of Experimental Animals of the Ocean University of China. This study was also approved by the Committee of the Ethics on Animal Care and Experiments at Ocean University of China (permit number: 20180101).

In short, the gill tissue $(1 \mathrm{~g})$ from the heavily WSSV-infected F. chinensis was homogenized in $10 \mathrm{ml}$ sterile prawn homoiosmotic phosphate buffered saline (PHPBS), and the homogenized solution was centrifuged at $600 \times \mathrm{g}$ for $20 \mathrm{~min}$ and filtered using a $450 \mathrm{~nm}$ membrane. The filtrate was centrifuged at $55000 \times \mathrm{g}$ for $1.5 \mathrm{~h}$ at $4^{\circ} \mathrm{C}$ to take the supernatant, and then the WSSV copies in inoculum was determined (39).

A total of 1400 healthy shrimp were divided into the control group and the WSSV infection group. In the WSSV infection group, 1100 shrimp were intramuscularly injected with $100 \mu \mathrm{l}$ WSSV inoculum (containing $10^{4}$ copies/ $\mu$ l), of which 950 shrimp were used for sampling, and the remaining 150 shrimp were 
divided into 3 groups on average for recording mortalities. In the control group, 300 shrimp were treated with the same amount of sterile PHPBS. The 150 shrimp were utilized to the sampling, and another 150 shrimp were also equally divided into 3 groups for recording the cumulative mortalities.

\section{Sampling of Hemocytes}

The hemocytes were collected at $0,6,12,18,24,36,48,60,72 \mathrm{~h}$ post infection (hpi) in the two groups, respectively. In the WSSV infection group, the hemocytes were collected from 30 shrimp and pooled as one separate sample, and a total 90 shrimp were sampled $(n=3)$ at each sampling point. In the control group, the hemocytes of 4 shrimp were used as one separate sample, and 12 shrimp were sampled $(n=3)$ at each time point. The modified cold Alsever solution ( $27 \mathrm{mM}$ Nacitrate, $336 \mathrm{mM} \mathrm{NaCl}, 115 \mathrm{mM}$ glucose, 9 mM EDTA, pH 7.2, AS) was used as anticoagulant, and the hemolymph was withdrawn from the pericardial cavity using a syringe containing the anticoagulant. Then, the collected hemocytes were centrifuged at $400 \times \mathrm{g}$ for $5 \mathrm{~min}$ at $4{ }^{\circ} \mathrm{C}$ and washed three times with sterile PHPBS. In addition, the total hemocytes count in hemolymph was calculated as previous method (35). Briefly, $10 \mu \mathrm{l}$ of hemocytes suspension was diluted for 10 times in $90 \mu \mathrm{l}$ PHPBS, then the density of the diluted hemocyte suspension was measured by Neubauer hemocytometer, and THC was obtained by calculation.

\section{Detection of Apoptotic Hemocytes by Flow Cytometric Immunofluorescence Assay (FCIFA)}

The DNA fragmentation due to cell death by apoptosis could be labeled with the TUNEL method (40). Therefore, the apoptotic hemocytes were detected by TUNEL Assay Kit (Biovision, USA) in combination with flow cytometry $(11,41)$. The $2 \%$ paraformaldehyde was used to fix approximately $10^{6}$ hemocytes for $15 \mathrm{~min}$, and then rinse twice with PHPBS. The fixed hemocytes were permeabilized with $0.1 \%$ TritonX-100 for 15 min. After rinsed with PHPBS twice, the pelleted hemocytes were resuspended in the DNA fragment labeling solution and incubated at $37^{\circ} \mathrm{C}$ for $1 \mathrm{~h}$. The TdT-enzyme negative solutions were used as controls. Following rinsed twice and precipitated, the hemocytes were incubated in $100 \mu$ l diluted Anti-BrdU-Red antibody solution at room temperature (RT) in the dark for 25 min. After rinsed and resuspended with PHPBS, it was analyzed by flow cytometer (Accuri C6, BD Biosciences, USA).

\section{Detection of WSSV-Positive Hemocytes by FCIFA}

The WSSV-positive hemocytes were labeled with mixed mouse anti-WSSV monoclonal antibodies (Mabs 1D5, 1G12, 3B7,) previously produced in our laboratory and analyzed by flow cytometry $(35,42,43)$. The hemocytes (about $10^{6}$ cells in total) were fixed and permeabilized as above. Then the hemocytes suspension was incubated with mixed diluted Mabs for $1 \mathrm{~h}$ at $37^{\circ} \mathrm{C}$. Following three rinses with PHPBS, the hemocytes suspension was incubated with goat anti-mouse IgG Alexa Fluor ${ }^{\circledR} 488$ antibody (Invitrogen) for $45 \mathrm{~min}$ at $37^{\circ} \mathrm{C}$ in the dark, and washed as above.
Then, the hemocytes were suspended in $1 \mathrm{ml}$ PHPBS and analyzed by Accuri C6 flow cytometer. The myeloma culture supernatant instead of anti-WSSV Mabs to be used as the control.

\section{Quantification of Apoptotic-Related Genes Expression and WSSV Copies in Hemocytes by RT-qPCR}

For total RNA isolation, the each hemocytes sample (about $10^{5}$ cells in total) was dissolved in TRIzol ${ }^{\circledR}$ reagent (Invitrogen, USA) and the quality and quantity of total RNA was examined by a Nanodrop 8000 spectrophotometer (Thermo Scientific, MA, USA). The singlestrand cDNA was synthesized using $2 \mu \mathrm{g}$ DNA-free RNA by MMLV reverse transcriptase reagent Kit (Promega, USA). Then the expression profiles of three apoptosis-related genes in hemocytes including Caspase (FcCaspase), Cellular Apoptosis Susceptibility Protein ( FCCAS) and translationally controlled tumor protein (FcTCTP) were detected by RT-qPCR with specific primers (shown in Table 1). The RT-qPCR was performed in triplicate using SYBR Green I Master mix (Roche, Basel, Switzerland) in a LightCycler ${ }^{\circledR} 480$ II Real Time PCR System (Roche, Basel, Switzerland). The procedures were performed as following: 1 cycle of $95^{\circ} \mathrm{C}$ for $5 \mathrm{~min}$ and 40 cycles of $95^{\circ} \mathrm{C}$ for $5 \mathrm{~s}$, annealing for $20 \mathrm{~s}$, and $78{ }^{\circ} \mathrm{C}$ for $1 \mathrm{~s}$. The $18 \mathrm{~S}$ rRNA was used as the reference gene. The relative gene expression levels were calculated by the $2^{-\triangle \triangle \mathrm{t}}$ method.

The WSSV copies in the samples were investigated according to the WSSV detection curve that established previously $(39,44)$. In short, the total genomic DNA of each hemocytes sample (about $10^{5}$ cells in total) was isolated using DNA extraction kit (Takara, Japan) and quantified by Nanodrop 8000 Spectrophotometer. Then 50 ng DNA was added into each qPCR premix with primer pairs (QVP28F and QVP28R, shown in Table 1) for amplification, the absolute quantification PCR was carried out and the data was analyzed as previously described (35).

\section{Detection of Apoptotic WSSV-Positive Hemocytes by Double Immunofluorescence Flow Cytometry and Immunofluorescent Assay (IFA)}

The prepared hemocytes (containing about $10^{7}$ cells) sampled at $0,6,12,18,24,36,48,60$ and 72 hpi was incubated with the mixed anti-WSSV Mabs for $1 \mathrm{~h}$ at $37^{\circ} \mathrm{C}$. Following rinses, the hemocytes were incubated with the goat anti-mouse IgG Alexa

TABLE 1 | Primers used in the present study.

\begin{tabular}{lll}
\hline Primer name & Primer sequence $\mathbf{( 5}^{\prime} \mathbf{-} \mathbf{3}^{\prime} \mathbf{)}$ & Application \\
\hline FCCaspase-F & AAGGGAATCCAAGGGAGTGTC & qRT-PCR primers \\
FCCaspase-R & ATCGGTTCGTAGAGGACTGC & \\
FCCAS-F & ACTTGCCCAGCCACTTACA & qRT-PCR primers \\
FCCAS-R & CTGGTAAGTCCTGCGAGTTAG & \\
FCTCTP-F & TGGCGTAATCTATGAAGTAACAGG & qRT-PCR primers \\
FCTCTP-R & CGAAAGCATAACCTTCTTGAGC & \\
18SrRNA-F & ACAATGGCTATCACGGGTAACG & Internal reference \\
18SrRNA-R & CTGCTGCCTTCCTTAGATGTGGTA & \\
QVP28F & AAACCTCCGCATTCCTGTGA & WSSV detection primers \\
QVP28R & TCCGCATCTTCTCCTCAT &
\end{tabular}


Fluor ${ }^{\circledR} 488$ for $45 \mathrm{~min}$ in the dark. Then, the hemocytes were incubated with the DNA fragment labeling solution. The pelleted hemocytes were suspended in $1 \mathrm{ml}$ PHPBS for analysis by Accuri C6 flow cytometer.

For microscopic immunofluorescence assay, approximately $10^{5}$ hemocytes sampled at $48 \mathrm{hpi}$ were settle onto glass slides and incubated with anti-WSSV Mabs at $37^{\circ} \mathrm{C}$ for $1 \mathrm{~h}$. Following washing with PHPBST (PHPBS containing 0.5\%o Tween-20), the hemocytes were incubated with goat anti-mouse IgG Alexa Fluor ${ }^{\circledR} 488$ at $37^{\circ} \mathrm{C}$ for $45 \mathrm{~min}$. Then the cells were rinsed and covered with DNA fragmentation labeling solution for $1 \mathrm{~h}$ incubation at $37^{\circ} \mathrm{C}$. Following rinses, $25 \mu \mathrm{l}$ Anti-BrdU-Red antibody solution was added at RT for $45 \mathrm{~min}$ incubation. Finally, the cells were stained with 4,6-diamidino-2-phenylindole dihydrochloride (DAPI). The hemocytes were observed under a fluorescence microscope (Olympus DP70, Japan).

\section{Calculation of Granulocytes and Hyalinocytes Densities by FCIFA}

The density of each hemocyte subpopulation was calculated by flow cytometer. The previously produced Mabs (1G8 and1H11) that could specifically recognize the granulocytes of $F$. chinensis were used to stain the granulocytes $(11,45,46)$. The hemocytes (containing about $10^{6}$ cells) sampled at $0,12,24,36,48,60$ and 72 hpi were incubated with diluted anti-granulocytes Mabs at $37^{\circ} \mathrm{C}$ for $1 \mathrm{~h}$. Following rinsed, the hemocytes suspension was incubated with Alexa Fluor ${ }^{\circledR} 488$ antibody for $45 \mathrm{~min}$ at $37^{\circ} \mathrm{C}$ in dark. Then, the hemocytes were resuspended for calculating the density of each hemocyte subpopulation by Accuri C6 flow cytometer.

\section{Detection of Apoptotic Granulocytes and Hyalinocytes by Double Immunofluorescence Flow Cytometry and IFA}

The dynamic change of the apoptotic different hemocyte subpopulations were analyzed by flow cytometry. The pretreated hemocytes (approximately $10^{7}$ cells) were first incubated with the anti-granulocytes Mabs and the Alexa Fluor ${ }^{\circledR} 488$ as described above. After that, the hemocytes were incubated with DNA fragment labeling solution and Anti-BrdU-Red antibody solution. The hemocytes suspension were analyzed by flow cytometer. For microscopic immunofluorescence assay, the hemocytes (approximately $10^{5}$ cells) sampled at $48 \mathrm{hpi}$ were fixed and settled onto slides. The hemocytes were successively incubated with antigranulocytes Mabs and Alexa Fluor ${ }^{\circledR} 488$. The hemocytes were sequentially covered with DNA fragmentation labeling solution and then with the Anti-BrdU-Red antibody solution. The cells were stained with DAPI. The apoptotic granulocytes and hyalinocytes were observed by fluorescence microscope.

\section{Detection of the WSSV-Positive Granulocytes and Hyalinocytes by Double Immunofluorescence Flow Cytometry and IFA}

The anti-WSSV Mabs were first fluorescently labeled by Alexa Fluor ${ }^{\circledR} 488$ Microscate Protein Labeling Kit (life technologies,
USA). $100 \mathrm{mg}$ of anti-WSSV Mabs was mixed with Alexa Fluor 488 fluorescein at 1:2 (w/w) and labeled for $2 \mathrm{~h}$. The mixture was filtered through a resin column to remove the remaining fluorescein and it was confirmed by fluorescence observation whether the antibody was successfully labeled with fluorescein. The WSSV-infected states of different hemocyte subpopulations were analyzed by double immunofluorescence flow cytometry. The pretreated hemocytes (approximately $10^{7}$ cells) sampled at 0,12 , $24,36,48,60$ and 72 hpi were consecutively incubated with antigranulocytes Mabs and Alexa Fluor ${ }^{\circledR} 647$. Then, the hemocytes were incubated with the fluorescent-labeled anti-WSSV Mabs. The hemocytes were rinsed and resuspended for analysis by flow cytometer. For microscopic immunofluorescence assay, the previously treated hemocytes were sequentially incubated with anti-granulocytes Mabs, the Alexa Fluor ${ }^{\circledR} 647$ and Alexa Fluor 488 labeled anti-WSSV Mabs. After DAPI staining, the hemocytes were observed by the fluorescence microscopy.

\section{Quantification of WSSV Copies in Granulocytes and Hyalinocytes by RT-qPCR}

The different hemocyte subpopulations sampled at $0,12,24,36$, $48,60,72$ hpi were sorted by immunomagnetic bead according to the method established by our laboratory, and then the numbers of WSSV copies in each hemocyte subpopulation were measured as described above $(11,44)$. Briefly, the hemocytes (about $10^{8}$ cells) at each time point were incubated with anti-granulocytes Mabs. Followed rinsed with magnetic activated cell sorting buffer (MACS), the hemocytes were then incubated with goat antimouse IgG magnetic beads (Miltenyi Biotec, Germany). The hemocytes flowed through a LS column (Miltenyi Biotecc, Germany), and collected. The collected granulocytes (magnetically labeled cells) and hyalinocytes (magnetically unlabeled cells) were separately purified by the new LS column. After labelling with goat anti-mouse IgG Alexa Fluor ${ }^{\circledR} 488$, the purity of sorted hemocyte subpopulation was analyzed by flow cytometry. The total genomic DNA of granulocytes and hyalinocytes were extracted and the WSSV copies in each hemocyte subpopulation sample was then determined by RT-qPCR according to the previous protocol and the results were analyzed by the established standard curve.

\section{Statistical Analysis}

The statistical analysis was performed using software SPSS (Version 20.0; SPSS, Inc), and statistical comparisons was performed with independent-samples t test. Data were given as arithmetic mean \pm S.D., and the $p<0.05$ were considered differences significant.

\section{RESULTS}

\section{The Change of Hemocyte Density and Shrimp Accumulative Mortality}

The density of total hemocytes begun to decline significantly since 12 hpi and dropped sharply to about $6 \%$ of the original 
hemocytes density at $48 \mathrm{hpi}$. The density of hemocytes dropped to the minimum value of $0.66 \pm 0.36 \times 10^{6} \mathrm{cell} / \mathrm{ml}$ at $72 \mathrm{hpi}$ (Figure 1A). The statistical results of the accumulative mortality in shrimp were shown in Figure 1B. Only three shrimp died in the control group. In contrast, the mortality of shrimp in the experimental group increased slightly within $36 \mathrm{hpi}$, and then increased sharply. At 72 hpi, the mortality was as high as $85 \%$.

\section{The Apoptotic Process of Hemocytes and Expression Profiles of Apoptosis-Related Genes}

The apoptotic hemocytes rate of shrimp in the infection group increased significantly and peaked at $6 \mathrm{hpi}$ with an apoptotic rate of $4.7 \pm 1.2 \%$, then decreased slightly. At 18 hpi and 24 hpi, there was no significant difference in the statistical results of apoptotic rates between the WSSV-infected group and the control group. From $24 \mathrm{hpi}$, the apoptotic rate of hemocytes in the WSSVinfected shrimp increased rapidly, and reached the second peak level with $22.2 \pm 3.0 \%$ at $48 \mathrm{hpi}$, then decline (Figure $\mathbf{2 A}$ ).

Compared with the control group, the expression profile of the three apoptosis-related genes of hemocytes in the experimental group changed dramatically. The FcCaspase was significantly up-regulated since $6 \mathrm{hpi}$, then decreased slightly, whereas no significant difference was found between the two groups at 24 hpi. Subsequently, the expression of FcCaspase in the experimental group increased rapidly, and the peak level occurred at $36 \mathrm{hpi}$, then exhibited a slight down-regulation (Figure 2B). As the apoptosis-inducing gene, the expression of FcCAS in WSSV infection group exhibited a slight up-regulated expression within $24 \mathrm{hpi}$, but there was no significant difference compared with the control group. However, the FcCAS began to up-regulate since $24 \mathrm{hpi}$, and the peak level occurred at $36 \mathrm{hpi}$ then underwent a gradual down-regulation (Figure 2C). The expression of the apoptotic inhibitor, TCTP, was notably lower than that of the PHPBS-injection group during the whole experimental period except for the time point of $24 \mathrm{hpi}$ (Figure 2D).

\section{WSSV Proliferation in Hemocytes}

The WSSV-positive hemocytes significantly increased since 6 hpi $(p<0.05)$, and reached the peak with an infection rate of $60.1 \pm$ $2.2 \%$ at $36 \mathrm{hpi}$, then maintained at a high level afterwards (Figure 3A). And the absolute qPCR assay showed that the WSSV copies did not show a significant increase within $18 \mathrm{hpi}$, but which significantly increased at $24 \mathrm{hpi}$ and reached a much higher level at $48 \mathrm{hpi}$, and then maintained afterwards (Figure 3B).

\section{The Dynamic Change of Apoptotic Rate in WSSV-Positive and WSSV-Negative Hemocytes}

It was observed by fluorescence microscope that the WSSVpositive hemocytes underwent different degrees of apoptosis. The most of hemocytes were observed to be apoptotic-positive and WSSV-positive cells with red and green fluorescence, while a small number of hemocytes appeared to be only apoptoticpositive cells with red fluorescent signal or only WSSV-positive cells with green fluorescent signal (Figure 4A). The results of double immunofluorescence flow cytometry showed that the apoptotic rate of WSSV-positive hemocytes had a slight increase within $12 \mathrm{hpi}$, but which was lower than WSSVnegative hemocytes. Subsequently, the apoptotic rate of uninfected hemocytes rapidly declined from 12 hpi to 24 hpi, while the apoptotic rate of infected hemocytes maintained at the level of $2.3 \pm 0.2 \%$ at $18 \mathrm{hpi}$ and $24 \mathrm{hpi}$, which were significantly higher than that of uninfected hemocytes. Since $24 \mathrm{hpi}$, the apoptotic rates of uninfected and infected hemocytes both significantly increased and reached their respective peak values of $5.9 \pm 0.3 \%$ and $16.2 \pm 0.2 \%$ at $48 \mathrm{hpi}$, and underwent a decline afterwards. It was worth noting that the apoptotic rate of WSSV-
A

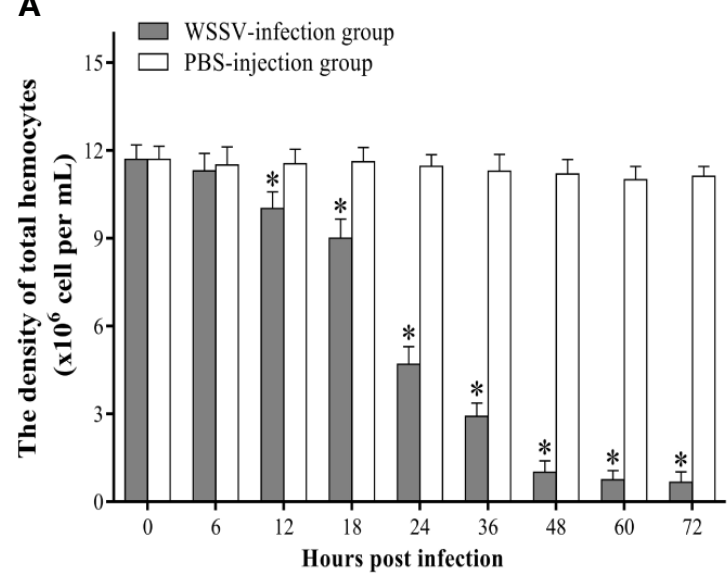

B

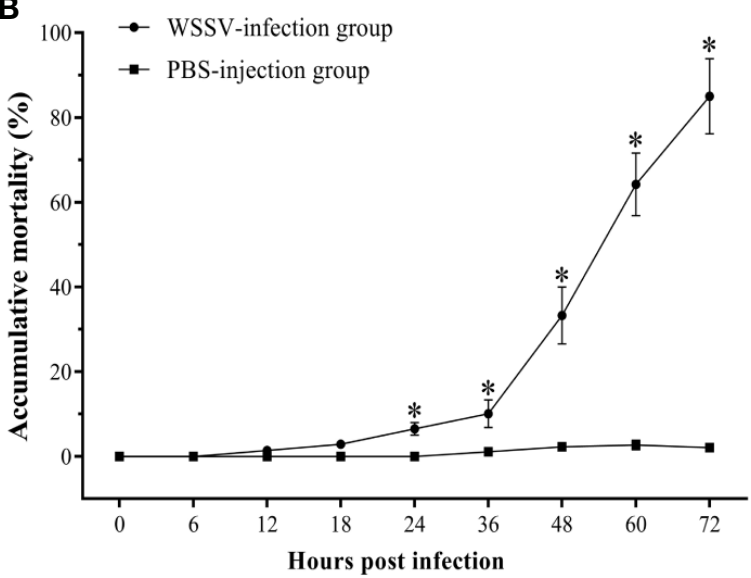

FIGURE 1 | The change of the hemocytes density (A) and accumulative mortality (B) of $F$. chinensis post WSSV infection. All values are expressed as arithmetic means $\pm S D(n=3)$. The asterisks indicate significant difference between WSSV-infection group and the control group $(p<0.05)$. 

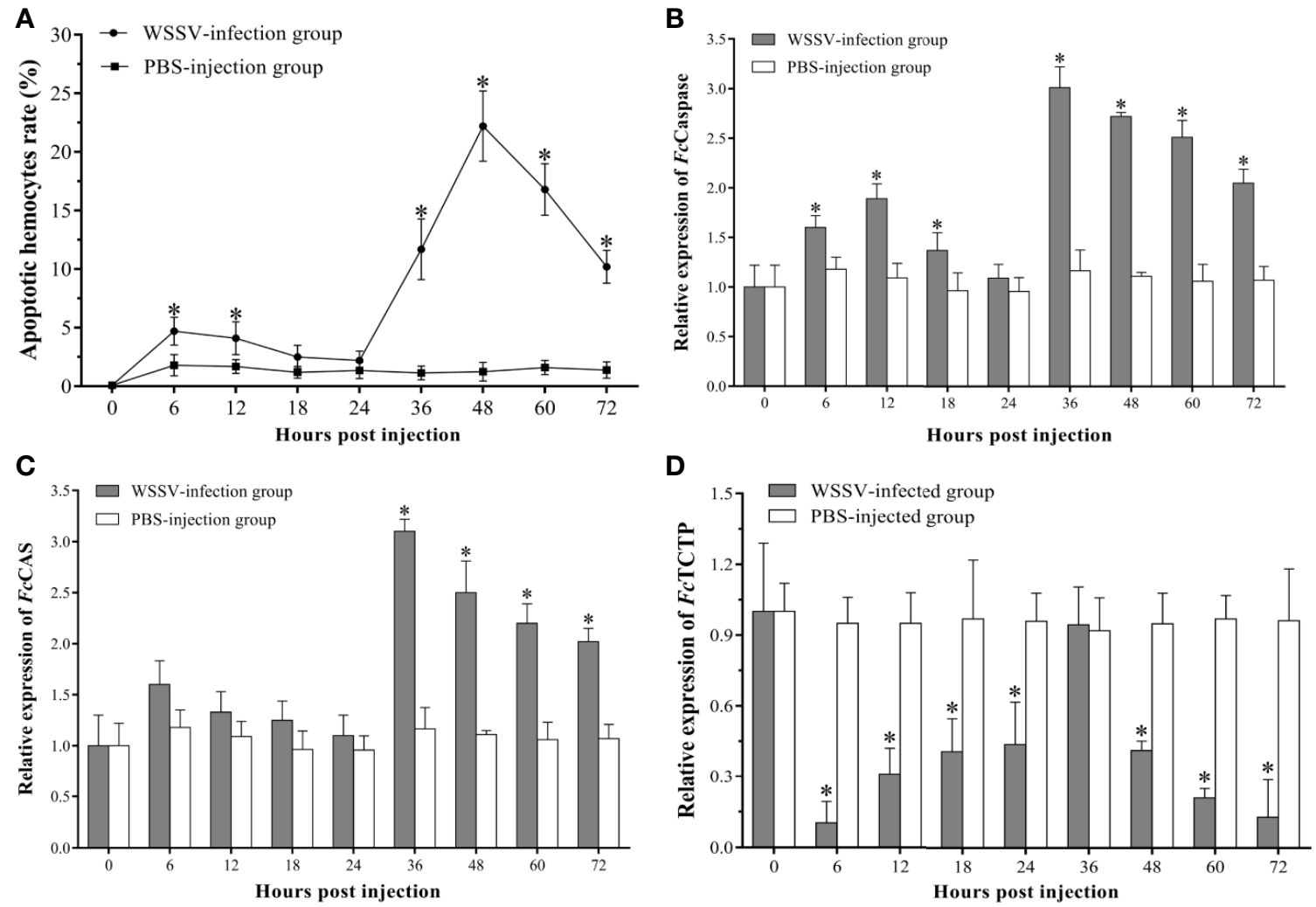

FIGURE 2 | The apoptosis dynamic of hemocytes in F. chinensis post WSSV infection. (A) Analysis of the apoptotic hemocytes rates by flow cytometry. (B-D) qRT$\mathrm{PCR}$ analysis of the expression levels of three apoptosis-related genes in hemocytes. All values are given as arithmetic mean \pm S.D ( $\mathrm{n}=3$ ). Significant differences are marked with asterisks, $p<0.05$.

positive hemocytes was significantly higher that of WSSVnegative hemocytes during this period (Figures 4B, C).

\section{The Time-Course Changes of the Densities and Apoptotic Rates of Granulocytes and Hyalinocytes}

The densities of granulocytes and hyalinocytes both exhibited a significant decreasing post WSSV infection, but with different decreasing rates. Since $12 \mathrm{hpi}$, the density of granulocytes underwent a rapid decline, and decreased to $0.14 \pm 0.03 \times 10^{6}$ cells per $\mathrm{ml}$ at 72 hpi (Figure 5A). Different from granulocytes, the density of hyalinocytes showed a more gradual and later decline, which was significantly decreased at $36 \mathrm{hpi}$, and then descend to $0.52 \pm 0.06 \times 10^{6}$ cells per $\mathrm{ml}$ at 72 hpi (Figure 5B).

In the hemocytes sampled at $48 \mathrm{hpi}$, it was observed that the number of apoptotic granulocytes with green and red fluorescent signals were significantly more than the apoptotic hyalinocytes with only red fluorescent signal (Figure 6A). According to the result of double immunofluorescence flow cytometry, the apoptotic rates of granulocytes and hyalinocytes increased within $12 \mathrm{hpi}$, while the apoptotic rate of granulocytes was significantly higher than that of hyalinocytes. At $24 \mathrm{hpi}$, the apoptotic rates of granulocytes and hyalinocytes were both underwent slight decrease. The apoptotic rates of granulocytes and hyalinocytes both showed rapid increases since $24 \mathrm{hpi}$, and reached their respective peak values of $18.0 \pm 2.1 \%$ and $4.0 \pm 1.5 \%$ at $48 \mathrm{hpi}$, then declined gradually. During the whole WSSV infection period, the granulocytes generally exhibited significantly higher apoptotic ratios than the hyalinocytes (Figures 6B, C).

\section{Proliferation Dynamic of WSSV in Granulocytes and Hyalinocytes}

At 48 hpi, more WSSV-positive granulocytes were observed than WSSV-positive hyalinocytes by fluorescence microscopy (Figure 7A). According to the result of flow cytometry, the percentage of WSSV-positive granulocytes raised from $12 \mathrm{hpi}$, and reached a value of $33.6 \pm 3.2 \%$ at $36 \mathrm{hpi}$, then were kept in the high level (Figures 7B, C). In contrast, the percentage of WSSV-positive hyalinocytes were always significantly lower than that of granulocytes during WSSV infection, which reached the peak value of $25.4 \pm 2.9 \%$ at 48 hpi (Figure 7C). Meanwhile, the immunomagnetic bead sorting was used for separating the two types of hemocyte subpopulations, and the purities of sorted granulocytes and hyalinocytes both reached more than $95 \%$ (Figure 8A), in which the WSSV copies were detected. According to the results of absolute qPCR assay, WSSV copies in both granulocytes and hyalinocytes increased rapidly since 24 
A

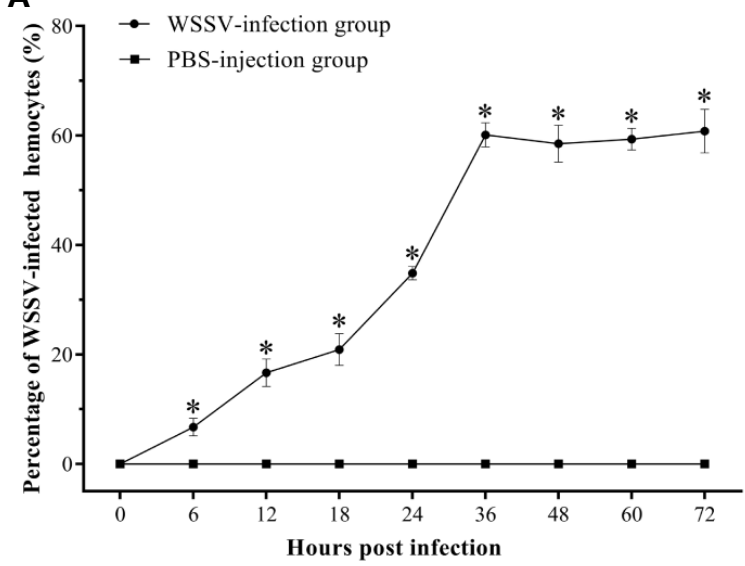

B

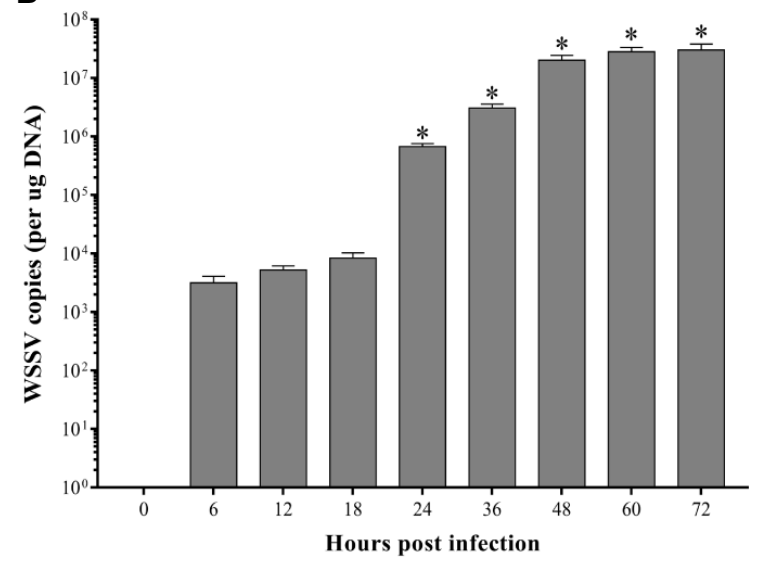

FIGURE 3 | Analysis of the virus-positive hemocytes in F. chinensis post WSSV infection by flow cytometry and absolute qRT-PCR. (A) The dynamic changes of the percentage of WSSV-positive hemocytes. (B) Absolute qPCR analysis of the WSSV proliferation in hemocytes. The asterisks indicate significant difference when compared with the 0 hpi $(p<0.05)$. All values are given as arithmetic mean \pm S.D $(n=3)$.
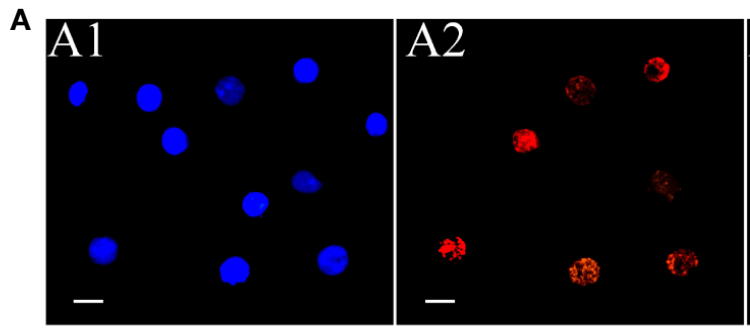

B
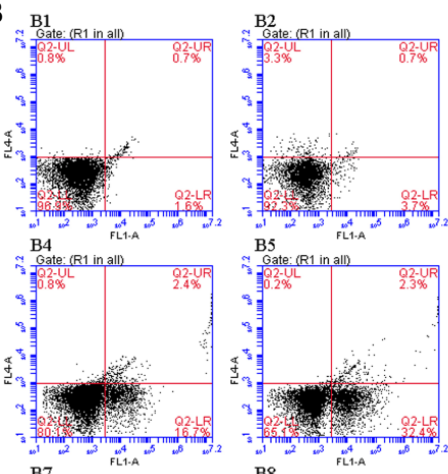

B5" Gate
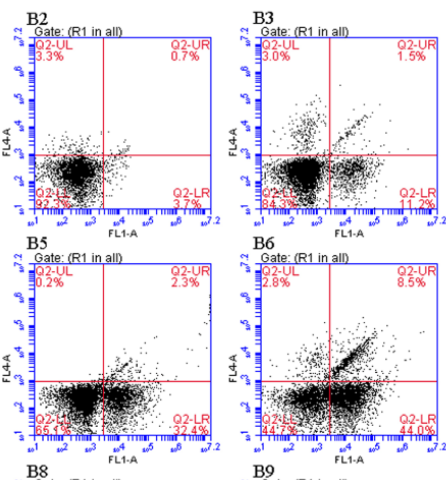

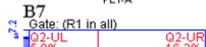
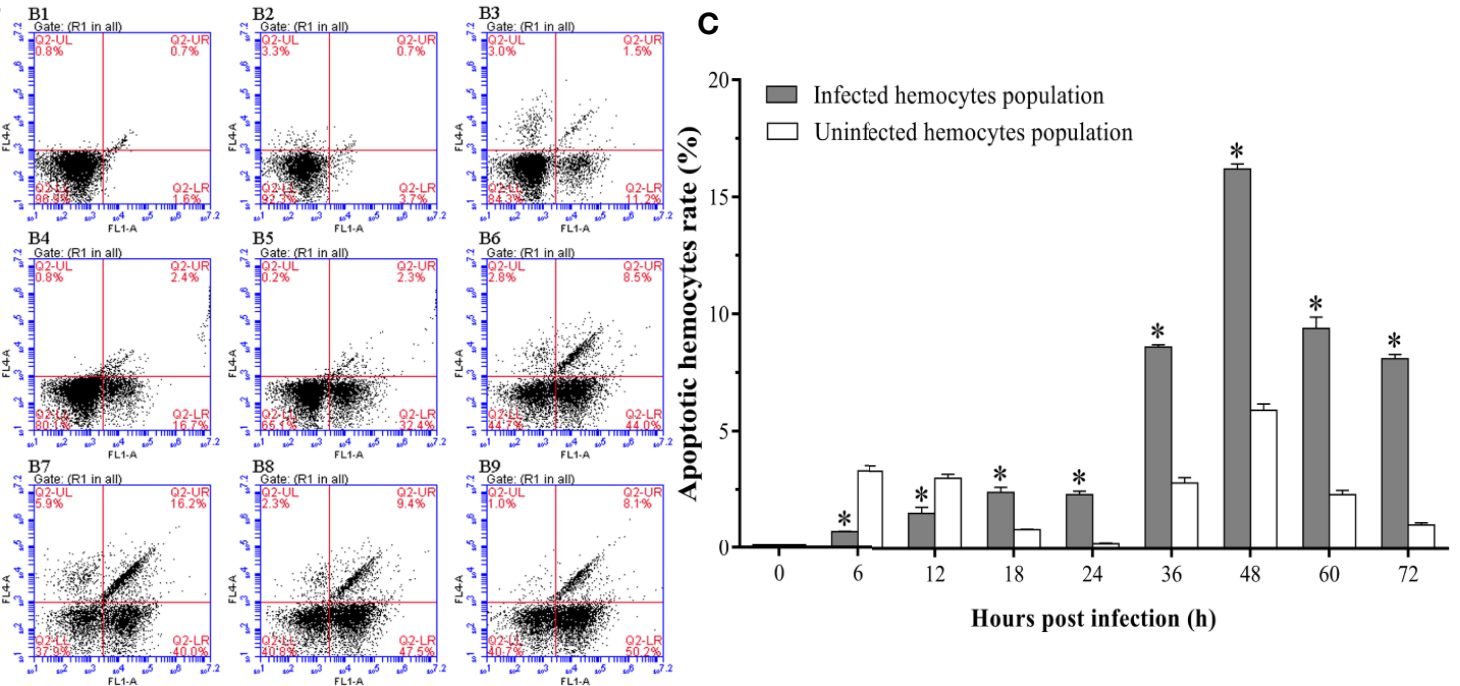

c
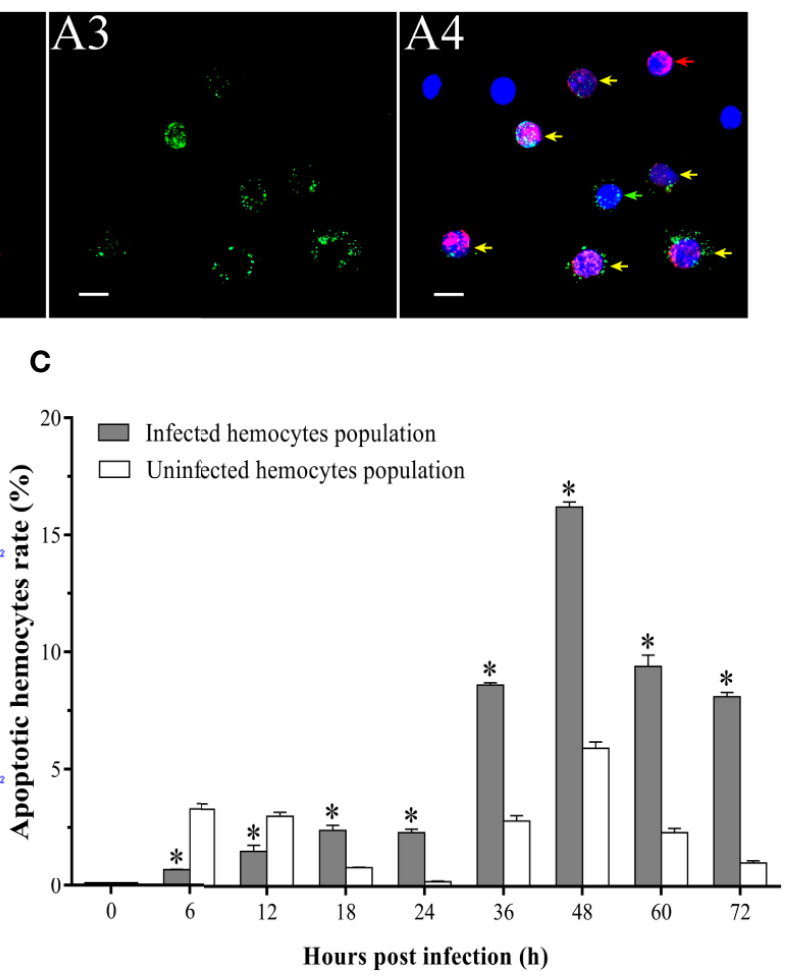

FIGURE 4 | Analysis of the apoptosis dynamic of WSSV-positive and WSSV-negative hemocytes by IFA and flow cytometry. (A) IFA analysis of apoptotic and/or WSSV-positive hemocytes sampled at 48 hpi. A1: DAPI stained the nucleus of hemocytes; A2: TUNEL stained apoptotic hemocytes; A3: Alexa Fluor ${ }^{\circledR} 488$ stained the WSSV-positive hemocytes; A4: The merge of A1, A2 and A3. Bars=10 $\mu \mathrm{m}$. The yellow arrows indicate apoptotic and WSSV-infected hemocytes; the red arrows indicate apoptotic WSSV-uninfected hemocytes; the green arrows indicate non-apoptotic WSSV-infected hemocytes. (B) Representative dot plots showing apoptotic rates of WSSV-infected and WSSV-uninfected hemocytes at 0, 6, 12, 18, 24, 36, 48, 60 and 72 hpi. Q2-LL: non-apoptotic and WSSV-uninfected hemocytes; Q2-LR: non-apoptotic and WSSV-infected hemocytes; Q2-UL: apoptotic and WSSV-uninfected hemocytes; Q2-UR: apoptotic and WSSV-infected hemocytes. (C) The apoptotic rates of WSSV-infected and WSSV-uninfected hemocytes. All values are given as arithmetic mean \pm S.D ( $\mathrm{n}=3$ ). Significant differences are marked with asterisks, $p<0.05$. 
A

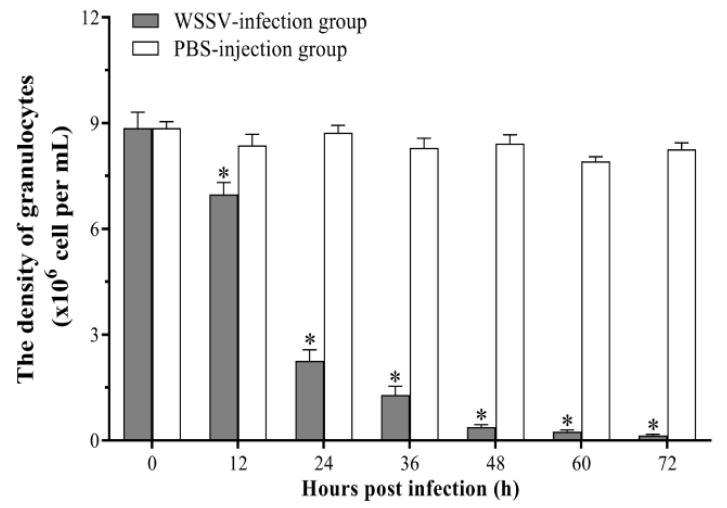

B

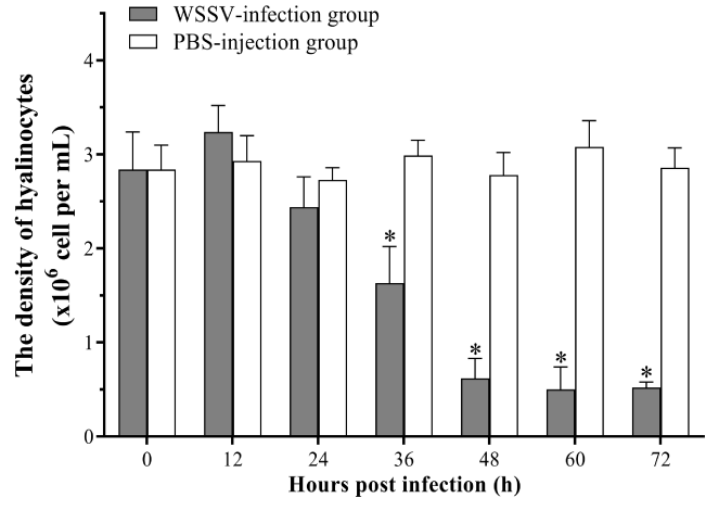

FIGURE 5 | Analysis of the densities of granulocytes and hyalinocytes in hemolymph post WSSV infection by flow cytometry. (A)Granulocytes. (B) Hyalinocytes. All values are given as arithmetic mean \pm S.D $(n=3)$. Significant differences are marked with asterisks, $p<0.05$.

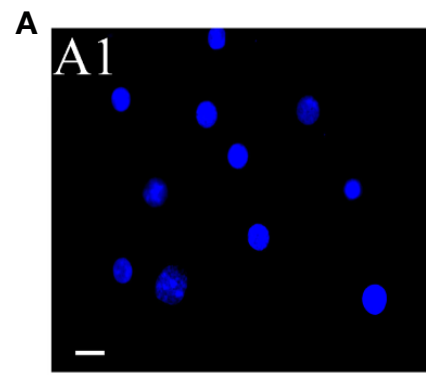

B
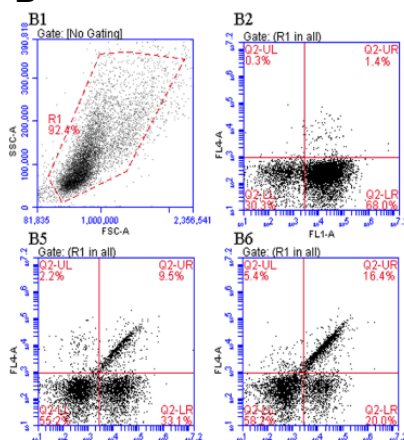

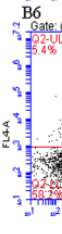
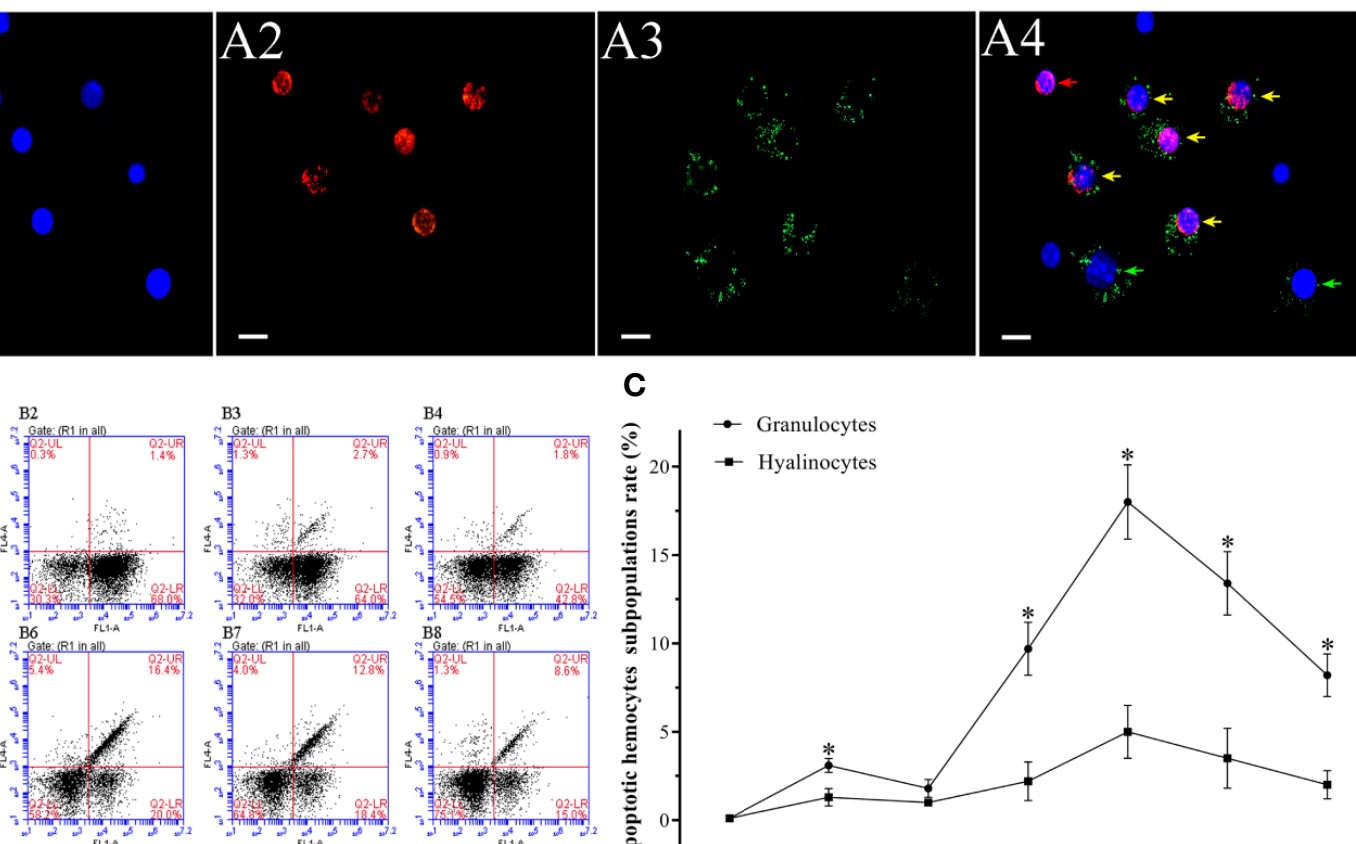

C
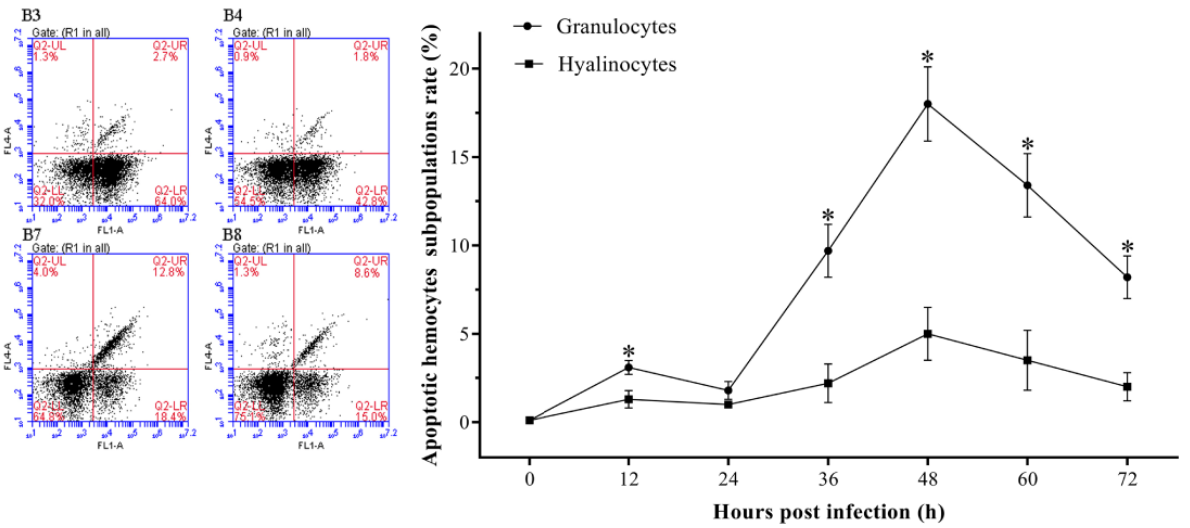

FIGURE 6 | Analysis of the apoptosis dynamics of granulocytes and hyalinocytes post WSSV infection by flow cytometry and IFA. (A) IFA analysis of apoptotic hemocyte subpopulations sampled at 48 hpi. A1: DAPI stained the nucleus of hemocytes; A2: TUNEL stained apoptotic hemocytes; A3: Alexa Fluor ${ }^{\circledR} 488$ stained granulocytes; A4: The merge of A1, A2 and A3. Bars $=10 \mu \mathrm{m}$. The yellow arrows indicate apoptotic granulocytes; the green arrows indicate non-apoptotic granulocytes; the red arrows indicate apoptotic hyalinocytes. (B) B1: Hemocytes were gated (R1) on FSC/SSC dot plots. B2-B8: Representative dot plots showing apoptotic rates of different hemocyte subpopulations at 0, 12, 24, 36, 48, 60 and 72 hpi. Q2-LL: non-apoptotic hyalinocytes; Q2-LR: non-apoptotic granulocytes; Q2-UL: apoptotic hyalinocytes; Q2-UR: apoptotic granulocytes. (C) The apoptotic rates of granulocytes and hyalinocytes. All values are given as arithmetic mean \pm S.D $(n=3)$. Significant differences between the two hemocyte subpopulations are marked with asterisks, $p<0.05$. 

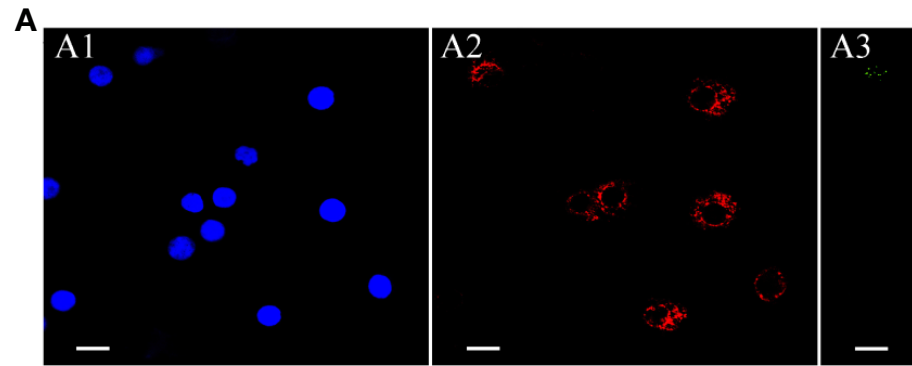

B
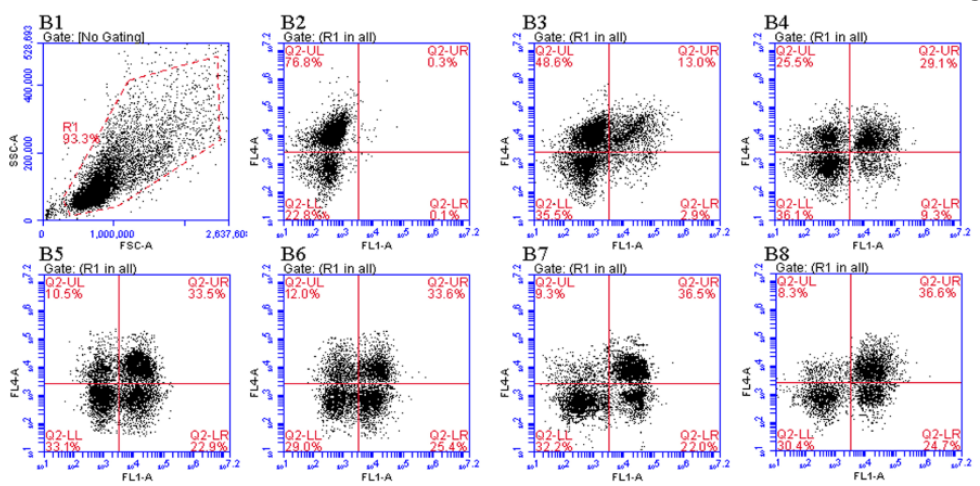

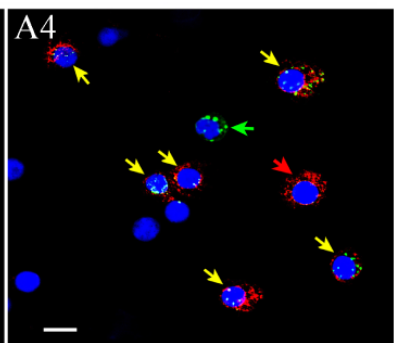

C

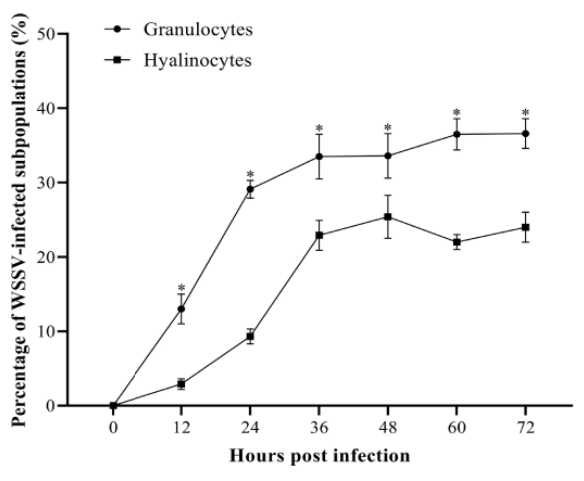

FIGURE 7 | Analysis of the infection rates of granulocytes and hyalinocytes post WSSV infection by flow cytometry and IFA. (A) IFA analysis of WSSV-infected hemocyte subpopulations sampled at 48 hpi. A1: DAPI stained the nucleus of hemocytes; A2: Granulocytes stained with Alexa Fluor ${ }^{\circledR} 647$; A3: WSSV-positive cells stained with anti-WSSV monoclonal antibody labeled Alexa Fluor ${ }^{\circledR} 488$; A4: The merge of A1, A2 and A3. Bars=10 $\mu$ m. The yellow arrows indicate WSSV-positive granulocytes; the red arrows indicate WSSV-negative granulocytes; the green arrows indicated WSSV-positive hyalinocytes, and cells without arrows were WSSVnegative hyalinocytes. (B) B1: Hemocytes were gated (R1) on FSC/SSC dot plots. B2-B8: Representative dot plots showing the percentages of WSSV-positive granulocytes and hyalinocytes at 0, 12, 24, 36, 48, 60 and 72 hpi. Q2-LL: WSSV-negative hyalinocytes; Q2-LR: WSSV-positive hyalinocytes; Q2-UL: WSSV-negative granulocytes; Q2-UR: WSSV-positive granulocytes. (C) The percentages of WSSV-positive granulocytes and hyalinocytes. All values are given as arithmetic mean \pm S.D $(n=3)$. Significant differences between the two hemocyte subpopulations are marked with asterisks, $p<0.05$.

hpi, and attained their peak levels at $36 \mathrm{hpi}$. It should be noticed that during WSSV infection, the numbers of WSSV copies in granulocytes was always significantly higher than that in hyalinocytes (Figure 8B).

\section{DISCUSSION}

As early as the 1990s, it was found that various tissues of WSSVinfected shrimp underwent varying degrees of apoptosis. And apoptosis was thought to be involved in the WSSV pathogenesis, which might be one of the main causes of death in shrimp post WSSV infection $(47,48)$. In another study, hemocytes apoptosis induced by yellow head virus (YHV) was also considered to be one of the main lethal causes for the infected Penaeus monodon (49). In the present work, the apoptotic rate of hemocytes in F. chinensis showed a significant increase post WSSV infection, and the total hemocytes density decreased markedly within $24 \mathrm{~h}$ hpi. Since $36 \mathrm{hpi}$, the apoptotic rate of hemocytes exhibited a rapid and significant increasing, then the density of hemocytes dropped rapidly and the shrimp had begun to die in large numbers. At 72 hpi, the density of hemocytes had been reduced to about $6 \%$ of normal level and the cumulative mortality of shrimp was as high as $85 \%$. These results indicated that the apoptosis of hemocytes has a close relationship with the death of shrimp post WSSV infection, which leads to a sharp decline in density of hemocytes and severely impaired normal physiological functions of shrimp.

As one of the major ways of programed cell death, apoptosis plays the vital role during virus infection (50). Apoptosis of virusinfected cells is one of the most primitive response of organisms to viral infection. Once the invaded virus was detected, apoptosis would be quickly triggered to eliminate virus-infected cells, thereby preventing the multiplication and spreading of viruses $(19,51)$. For example, apoptosis could effectively prevent the spreading of virus in the early stage of hepatitis B virus infection, and it is also considered that the apoptosis is the main defense mechanism to inhibit virus replication during the influenza A virus infection $(52,53)$. However, studies have found that viruses have developed strategies to evade or prevent apoptosis, thereby allowing themselves to proliferate or to promote persistent infection (51). For human cytomegalovirus, myxoma virus and Epstein-Barr virus, a variety of anti-apoptotic proteins have been found to inhibit premature host cell apoptosis for facilitating viral multiplication (54-56). Meanwhile, viruses could also induce host cell apoptosis to decomposite the infected cells, thereby favoring dissemination, such as feline calicivirus, oncolytic reovirus, and 

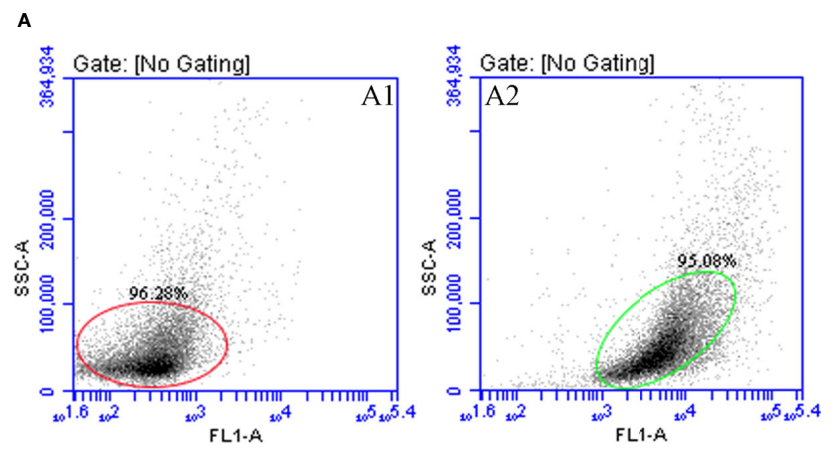

B

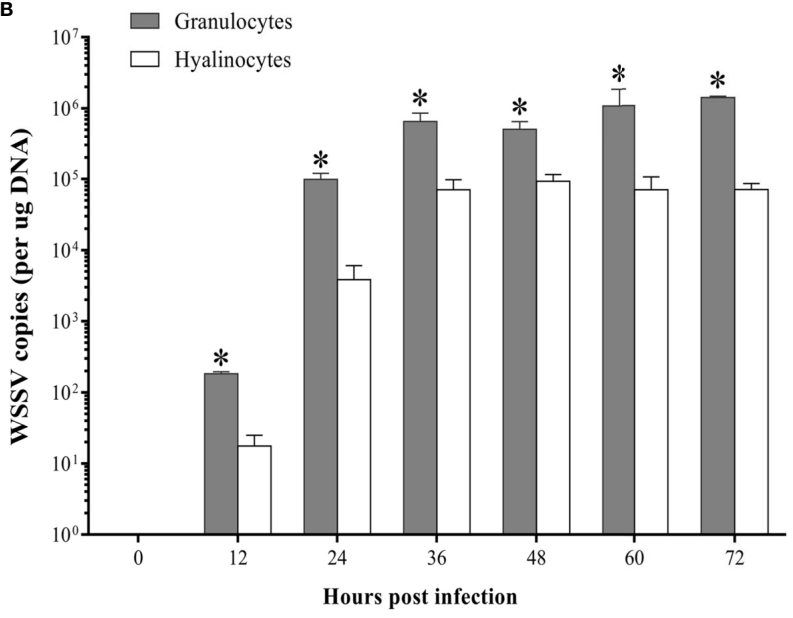

FIGURE 8 | The WSSV proliferation in granulocytes and hyalinocytes. (A) The purities of hyalinocytes and granulocytes after sorting by flow cytometry. A1: Hyalinocytes; A2: Granulocytes. (B) Absolute qPCR analysis of the WSSV proliferation in hyalinocytes and granulocytes. The asterisks indicate significant difference between two hemocyte subpopulations $(p<0.05)$. All values are given as arithmetic mean \pm S.D $(n=3)$.

porcine reproductive and respiratory syndrome virus (51, 57-59). WSSV also appears to be able to manipulate apoptosis of the host cell to provide itself with conditions for further invasion (60). Some proteins of WSSV have been found to have effects of inhibiting or promoting apoptosis in host cells during different infection stages, such as WSSV449 (also known as ORF390 or AAP-1), WSSV222, and ICP11 (61-63). WSSV449 could bind to Caspase to negatively regulate its activity and directly inhibit apoptosis. WSSV222 could inhibit apoptosis via degradation of the tumor suppressor-like protein (TSL, pro-apoptotic protein). Conversely, ICP11 is capable of binding to histones in the host cells to induce apoptosis at the late stage of WSSV infection. In this study, the apoptotic hemocytes rate increased rapidly at $6 \mathrm{hpi}$. During this period, Caspase and pro-apoptotic gene CAS were also significantly up-regulated, while the apoptosis-inhibiting gene TCTP was markedly down-regulated. The similar results were also found in our previous study in Litopenaeus vannamei (35). The results suggested that the hemocytes might exert antiviral effects through activating apoptosis during this stage. From $12 \mathrm{hpi}$ to 24 hpi, the apoptotic rate showed a slight decrease, and the expression levels of pro-apoptotic genes also declined, while the expression of apoptotic inhibiting gene increased slightly. The percentage of WSSV-infected hemocytes increased significantly during this period. These results suggested that WSSV might inhibit apoptosis by manipulating apoptosis-related genes of host cells $(34,64)$. Since $24 \mathrm{hpi}$, the WSSV copies in hemocytes increased significantly, indicating that WSSV had completed replication (65). And the apoptotic rate of hemocytes also increased sharply, as did the expression of pro-apoptotic genes. During this period, apoptosis seems to be utilized by WSSV to release its progeny virus $(32,66)$. Consistent with previous studies, the virus might manipulate a delicate balancing act between inhibition and induction of apoptosis in host cells to facilitate their infections (67).

Interestingly, our results showed that the apoptotic rate of WSSV-negative hemocytes was significantly higher than that of WSSV-positive hemocytes within $12 \mathrm{hpi}$, whereas which subsequently had a slight decline to a level lower than that of WSSV-positive cells. Since $24 \mathrm{hpi}$, the apoptotic rates of WSSVnegative and WSSV-positive hemocytes began to rise and both peaked at $48 \mathrm{hpi}$, then decreased. These results are consistent with our previous finding of WSSV-induced hemocytes apoptosis in L. vannamei (35). Similarly, when WSSV infected Penaeus monodon and Penaeus japonicas, apoptosis was firstly observed in the cells without WSSV particles $(28,68)$. Virusinduced apoptosis of virus-negative cells could lead to host immunodeficiency and damage the host immune system (69). The apoptosis of uninfected T cells in the early HIV (human immunodeficiency virus) infection stage are the main cause of the decline in host immunity (70). And the first to be apoptotic is the viral-negative cells when the host is infected with Herpes Simplex Virus (HSV) and measles virus, then the host immune system is destroyed $(71,72)$. Meanwhile, the apoptosis of viruspositive cells is one of the essential immune defense strategies of organism to restrict virus replication in the initial stage of viral invasion, which has been fully confirmed $(73,74)$. We speculated that in the early infection stage, WSSV caused apoptosis in WSSV-negative hemocytes to weaken shrimp immunity, providing conditions for its own proliferation. During this period, apoptosis of WSSV-positive hemocytes was a critical antiviral response to eliminate the invaded virus. In the middle and late infection stages, the virus-induced apoptosis would accelerate the virus-infected hemocytes to release the progeny virus and facilitated the spreading of WSSV.

The hemocyte subpopulations were demonstrated to not only have their specifically morphological features but also play distinct roles in immunity. Granulocytes with highly refractive granules contain components of the prophenoloxidase (proPO) system, which mainly exhibit cytotoxic effects on invading pathogens. They have also proven to be the main sites for the storage and release of antimicrobial peptides and lectins. The hyalinocytes are considered the main phagocytes $(15,75)$. It was reported that hemocyte subpopulations also had differential responses to pathogen invasion. When spiroplasma infected Macrobrachium rosenbergii, the count of granulocytes increased sharply, showing a much stronger response (76). The degranulation effect of 
granulocytes in L. vannamei was significantly increased during Gram-negative bacteria infection, and the content of proPO in hemolymph was increased to resist bacterial invasion (77). The YHV infection could cause a more severe response of proteins expression profiles in granulocytes of black tiger shrimp (78). Similarly, it was also found in our previous studies that WSSV infection caused stronger protein responses in granulocytes of $F$. chinensis (13). In the present work, compared with hyalinocytes, the granulocytes showed a more rapid and significant decreasing post WSSV infection, and also had a significantly higher apoptotic rate, which indicated that granulocytes were responding more actively to WSSV infection. While the apoptotic rate of hyalinocytes did not show significant changes during early infection stage, and a slight increase in density of hyalinocytes might be due to a phagocytosis requirement in response to WSSV infection (75). Since $36 \mathrm{hpi}$, the apoptotic rates of granulocytes and hyalinocytes both increased significantly, whereas the apoptotic rate of granulocytes during this period was significantly higher than hyalinocytes, and the density of the granulocytes also decreased more severely. These results suggested that granulocytes were more vulnerable to WSSV infection and exhibited stronger apoptotic response compared with hyalinocytes during WSSV infection.

Hemocyte subpopulations seem to be differentially susceptible to pathogens invasion and proliferation. It was found that the adhesion protein for Vibrio alginolyticus was mainly expressed in granulocytes of L. vannamei, indicating the granulocytes were more susceptible to $V$. alginolyticus adhesion (79). In crayfish, the key invasive proteins including peroxinectin and heat shock protein also exhibited a much higher expression in response to Spiroplasma eriocheiris infection (80). The yellow head virus was detected to be mainly proliferate in the granulocytes of black tiger shrimp (78). WSSV has previously been confirmed to propagate primarily in the granulocytes of Penaeus merguiensis (36). In the present work, we also found that the percentage of WSSV-positive granulocytes and the numbers of WSSV copies in granulocytes were always notably higher than that of hyalinocytes during the WSSV infection process, which indicated that granulocytes were more susceptible to WSSV infection. The differential susceptibility to WSSV might also be an important reason for the differential apoptotic responses between the two types of hemocyte subpopulations.

In summary, we found that hemocytes apoptosis might play different roles in the different WSSV infection stages. WSSV infection induced differential apoptotic responses between granulocytes and hyalinocytes, and granulocytes appeared to be more susceptible to WSSV infection and exhibited stronger apoptotic responses. The relevant results fully confirmed the

\section{REFERENCES}

1. Johansson MW, Keyser P, Sritunyalucksana K, Söderhäll K. Crustacean haemocytes and haematopoiesis. Aquaculture (1992) 191:0-52. doi: 10.1016/S0044-8486(00)00418-X

2. Söderhäll K. Crustacean immunity. Annu Rev Fish Dis (1992) 2:3-23. doi: 10.1016/0959-8030(92)90053-Z

3. Wang XW, Wang JX. Diversity and multiple functions of lectins in shrimp immunity. Dev Comp Immunol (2013) 39:27-38. doi: 10.1016/j.dci.2012.04.009 close relationship between the pathogenicity and lethal mechanism of WSSV and apoptosis. This research would deepen our thorough comprehension of the intimate relationship between apoptosis in hemocytes and WSSV infection, and facilitate us to understand the functional differences of hemocyte subpopulations in innate immunity of shrimp.

\section{DATA AVAILABILITY STATEMENT}

The raw data supporting the conclusions of this article will be made available by the authors, without undue reservation.

\section{ETHICS STATEMENT}

The animal study was reviewed and approved by the Committee of the Ethics on Animal Care and Experiments at Ocean University of China.

\section{AUTHOR CONTRIBUTIONS}

CC and QL designed the study, performed experiments and statistically analyzed the results, and drafted and revised the manuscript. XT guided and designed the study, and drafted and revised the manuscript. JX and XS provided research thought and helped experimental data processing. WZ provides research thought and provides reagents and experimental space. All authors contributed to the article and approved the submitted version.

\section{FUNDING}

The research was supported by the National key Research and Development Program of China (2018YFD0900504), Qingdao National Laboratory for Marine Science and Technology (QNLM2016ORP0307) and the Taishan Scholar Program of Shandong Province.

\section{SUPPLEMENTARY MATERIAL}

The Supplementary Material for this article can be found online at: https://www.frontiersin.org/articles/10.3389/fimmu.2020. 594390/full\#supplementary-material
4. Amparyup P, Kondo H, Hirono I, Aoki T, Tassanakajon A. Molecular cloning, genomic organization and recombinant expression of a crustin-like antimicrobial peptide from black tiger shrimp Penaeus monodon. Mol Immunol (2008) 45:1085-93. doi: 10.1016/j.molimm.2007.07.031

5. Gan ZT. The Role of Antimicrobial Peptides in Innate Immunity. Integr Comp Biol (2003) 43:300-4. doi: 10.1093/icb/43.2.300

6. Jiravanichpaisal P, Lee BL, Söderhäll K. Cell-mediated immunity in arthropods: Hematopoiesis, coagulation, melanization and opsonization. Immunobiology (2006) 211:230-6. doi: 10.1016/j.imbio.2005.10.015 
7. Li FH, Xiang JH. Recent advances in researches on the innate immunity of shrimp in China. Dev Comp Immunol (2013) 39:11-26. doi: 10.1016/ j.dci.2012.03.016

8. Söderhäll K, Smith VJ. Separation of the haemocyte populations of Carcinus Maenas and other marine decapods, and prophenoloxidase distribution. Dev Comp Immunol (1983) 7:229-39. doi: 10.1016/0145-305X(83)90004-6

9. Yao CL, Li FH, Xiang JH. Crustacean haemocytes and their function in immune responses. Zoological Res (2006) 27:549-57.

10. Yang CC, Lu CL, Chen S, Liao WL, Chen SN. Immune gene expression for diverse haemocytes derived from pacific white shrimp, Litopenaeus vannamei. Fish Shellfish Immunol (2015) 44:265-71. doi: 10.1016/j.fsi.2015.02.001

11. Xing J, Chang YH, Tang XQ, Sheng XZ, Zhan WB. Separation of haemocyte subpopulations in shrimp Fenneropenaeus chinensis by immunomagnetic bead using monoclonal antibody against granulocytes. Fish Shellfish Immunol (2017) 60:114-8. doi: 10.1016/j.fsi.2016.11.034

12. Zhu L, Chang YH, Xing J, Tang XQ, Sheng XZ, Zhan WB. Comparative proteomic analysis between two haemocyte subpopulations in shrimp Fenneropenaeus chinensis. Fish Shellfish Immunol (2018) 72:325-33. doi: 10.1016/j.fsi.2017.09.074

13. Zhu L, Tang XQ, Xing J, Sheng XZ, Zhan WB. Differential proteome of haemocyte subpopulations responded to white spot syndrome virus infection in Chinese shrimp Fenneropenaeus chinensis. Dev Comp Immunol (2018) 84:82-93. doi: 10.1016/j.dci.2018.02.003

14. Kobayashi M, Johansson MW, Söderhäll K. The $76 \mathrm{kD}$ cell-adhesion factor from crayfish haemocytes promotes encapsulation in vitro. Cell Tissue Res (1990) 260:13-8. doi: 10.1007/BF00297485

15. Vargas-Albores F, Gollas-Galván T, Hernández-López J. Functional characterization of Farfantepenaeus californiensis, Litopenaeus vannamei and L. stylirostris haemocyte separated using density gradient centrifugation. Aquaculture Res (2015) 36:352-60. doi: 10.1111/j.1365-2109.2004.01207.x

16. Omori SA, Martin GG, Hose JE. Morphology of hemocyte lysis and clotting in the ridgeback prawn, Sicyonia ingentis. Cell Tissue Res (1989) 255:117-23. doi: 10.1007/BF00229072

17. Zhang YW, Lai HWL, Yew DT. Apoptosis-a brief review. Neuroembryol Aging (2004) 05:47-59. doi: 10.1159/000085404

18. Williams GT. Programmed cell death: apoptosis and oncogenesis. Cell (1991) 65:1097-8. doi: 10.1016/0092-8674(91)90002-g

19. Everett H, Mcfadden G. Apoptosis: an innate immune response to virus infection. Trends Microbiol (1999) 7:160-5. doi: 10.1016/S0966-842X(99) 01487-0

20. Clarke TE, Clem RJ. Insect defenses against virus infection: the role of apoptosis. Int Rev Immunol (2003) 22:401-24. doi: 10.1080/08830180305215

21. Hay S, Kannourakis G. A time to kill: Viral manipulation of the cell death program. J Gen Virol (2002) 83:1547-64. doi: 10.1099/0022-1317-83-7-1547

22. Latif RS, Wu JL, Wang HV, Hong JR. Aquatic viruses induce host cell death pathways and its application. Virus Res (2016) 211:133-44. doi: 10.1016/ j.virusres.2015.10.018

23. Amara A, Mercer J. Viral apoptotic mimicry. Nat Rev Microbiol (2015) 13:461-9. doi: 10.1038/nrmicro3469

24. Best SM, Bloom ME. Caspase activation during virus infection: more than just the kiss of death? Virology (2004) 320:191-4. doi: 10.1016/j.virol.2003.11.025

25. Best SM. Viral Subversion of Apoptotic Enzymes: Escape from Death Row. Annu Rev Microbiol (2008) 62:171-92. doi: 10.1146/annurev.micro.62.081307.163009

26. Stentiford GD, Neil DM, Peeler EJ, Shields JD, Small HJ, Flegel TW, et al. Disease will limit future food supply from the global crustacean fishery and aquaculture sectors. J Invertebrate Pathol (2012) 110:141-57.23. doi: 10.1016/ j.jip.2012.03.013

27. Rajan PR, Ramasamy P, Purushothaman V, Brennan GP. White spot baculovirus syndrome in the Indian shrimp Penaeus monodon and P. indicus. Aquaculture (2000) 184:0-44. doi: 10.1016/S0044-8486(99)00315-4

28. Wongprasert K, Khanobdee K, Glunukarn SS, Meeratana P, Withyachumnarnkul B. Time-course and levels of apoptosis in various tissues of black tiger shrimp Penaeus monodon infected with white-spot syndrome virus. Dis Aquat Organisms (2003) 55:3-10. doi: 10.3354/dao055003

29. Chen J, Gong Y, Zheng H, Ma H, Aweya JJ, Zhang Y, et al. SpBcl2 promotes WSSV infection by suppressing apoptotic activity of hemocytes in mud crab, Scylla paramamosain. Dev Comp Immunol (2019) 100:103421. doi: 10.1016/ j.dci.2019.103421
30. Yuan FH, Chen YG, Zhang ZZ, Yue HT, Bi HT, Yuan K, et al. Downregulation apoptosis signal-regulating kinase 1 gene reduced the Litopenaeus vannamei hemocyte apoptosis in WSSV infection. Fish Shellfish Immunol (2016) 50:109-16. doi: 10.1016/j.fsi.2015.12.003

31. Rijiravanich ABCL, Withyachumnarnkul B. Knocking down caspase-3 by RNAi reduces mortality in Pacific white shrimp Penaeus (Litopenaeus) vannamei challenged with a low dose of white-spot syndrome virus. Fish Shellfish Immunol (2008) 24:308-13. doi: 10.1016/j.fsi.2007.11.017

32. Leu JH, Lin SJ, Huang JY, Chen TC, Lo CF. A model for apoptotic interaction between white spot syndrome virus and shrimp. Fish Shellfish Immunol (2013) 34:1011-7. doi: 10.1016/j.fsi.2012.05.030

33. Zhang XB, Wang L, Zhi B, Wu W. Requirement for shrimp caspase in apoptosis against virus infection. Dev Comp Immunol (2008) 32:706-15. doi: 10.1016/j.dci.2007.10.010

34. He F, Fenner BJ, Godwin AK, Kwang J. White Spot Syndrome Virus Open Reading Frame 222 Encodes a Viral E3 Ligase and Mediates Degradation of a Host Tumor Suppressor via Ubiquitination. J Virol (2006) 80:3884-92. doi: 10.1128/JVI.80.8.3884-3892.2006

35. Tang XQ, Cui C, Liang QR, Sheng XZ, Xing J, Zhan WB. Apoptosis of hemocytes is associated with the infection process of white spot syndrome virus in Litopenaeus vannamei. Fish Shellfish Immunol (2019) 94:907-15. doi: 10.1016/j.fsi.2019.10.017

36. Wang YT, Liu W, Seah JN, Lam CS, Xiang JH, Korzh V, et al. White spot syndrome virus (WSSV) infects specific hemocytes of the shrimp Penaeus merguiensis. Dis Aquat Organisms (2002) 52:249. doi: 10.3354/dao052249

37. Jiravanichpaisal $P$, Sricharoen $S$, Söderhäll $K$. White spot syndrome virus (WSSV) interaction with crayfish haemocytes. Fish Shellfish Immunol (2006) 20:718-27. doi: 10.1016/j.fsi.2005.09.002

38. Lo CF, Leo JH, Ho CH, Chen CH, Peng SE, Chen YT, et al. Detection of baculovirus associated with white spot syndrome (WSBV) in penaeid shrimps using polymerase chain reaction. Dis Aquat Organisms (1996) 25:133-41. doi: 10.3354/dao025133

39. Yuan L, Zhang X, Chang M, Jia C, Hemmingsen SM, Dai H. A new fluorescent quantitative PCR-based in vitro neutralization assay for white spot syndrome virus. J Virol Methods (2007) 146:96-103. doi: 10.1016/j.jviromet.2007.06.009

40. Sahtout AH, Hassan MD, Shariff M. DNA fragmentation, an indicator of apoptosis, in cultured black tiger shrimp Penaeus monodon infected with white spot syndrome virus (WSSV). Dis Aquat Organisms (2001) 44:155-9. doi: $10.3354 /$ dao 044155

41. Feng JX, Tang XQ, Zhan WB. Analysis and identification of tyrosine phosphorylated proteins in hemocytes from Fenneropenaeus chinensis (Decapoda: Penaeidae) infected with white spot syndrome virus. J Crustacean Biol (2014) 34:453-9. doi: 10.1163/1937240X-00002241

42. Wang YN, Zhan WB, Xing J, Jiang YS. In vivo neutralization assays by monoclonal antibodies against white spot syndrome virus in crayfish (Cambarus proclarkii). Acta Oceanol Sin (2018) 2:131-7.

43. Jiang YS, Zhan WB, Sheng XZ. Neutralizing assay of monoclonal antibodies against white spot syndrome virus (WSSV). Aquaculture (2007) 272:216-22. doi: 10.1016/j.aquaculture.2007.07.229

44. Zhang L, Tang XQ, Sheng XZ, Zhan WB. Analysis on Dynamic Changes of WSSV Amount in Procambarus clarkii through Quantitative Real-time PCR. China Anim Health Inspec (2015) 32:69-74. doi: 10.1016/j.aquaculture.2007.07.229

45. Zhan WB, Wei XL, Xing J, Zhang ZD. Characterization of monoclonal antibodies to haemocyte types of the shrimp, Fenneropenaeus chinensis. Crustaceana (2008) 81:931-42. doi: 10.1163/156854008X354993

46. Lin YB, Zhan WB, Li Q, Zhang ZD, Wei XM, Sheng XZ. Ontogenesis of haemocytes in shrimp (Fenneropenaeus chinensis) studied with probes of monoclonal antibody. Dev Comp Immunol (2007) 31:1073-81. doi: 10.1016/ j.dci.2007.02.001

47. Flegel TW, Pasharawipas T. Active viral accommodation: a new concept for crustacean response to viral pathogens. Adv Shrimp Biotechnol (1998) 245-50.

48. Rhee WJ, Park TH. Flow cytometric analysis of the effect of silkworm hemolymph on the baculovirus-induced insect cell apoptosis. J Microbiol Biotechnol (2001) 11:853-7.

49. Khanobdee K, Soowannayan C, Flegel TW, Ubol S, Withyachumnarnkul B. Evidence for apoptosis correlated with mortality in the giant black tiger shrimp Penaeus monodon infected with yellow head virus. Dis Aquat Organisms (2002) 48:79-90. doi: 10.3354/dao048079 
50. Hardwick MJ. Apoptosis in viral pathogenesis. Cell Death Differ (2001) 8 (2):109-10. doi: 10.1038/sj.cdd.4400820

51. Zhou X, Jiang W, Liu Z, Liu S, Liang X. Virus infection and death receptormediated apoptosis. Viruses (2017) 9(11):316. doi: 10.3390/v9110316

52. Silke A, Hösel M, Protzer U. Apoptosis of hepatitis B virus-infected hepatocytes prevents release of infectious virus. J Virol (2010) 84 (22):11994-2001. doi: 10.1128/JVI.00653-10

53. Ampomah $\mathrm{PB}$, Lina HK. Influenza A virus-induced apoptosis and virus propagation. Apoptosis (2020) 25.1:1-11. doi: 10.1007/s10495-019-01575-3

54. Goldmacher VS, Bartle LM, Skaletskaya A, Dionne CA, Kedersha NL, Vater CA, et al. A cytomegalo virus encoded mitochondria-localized inhibitor of apoptosis structurally unrelated to Bcl-2. Proc Natl Acad Sci (1999) 96 (22):12536-41. doi: 10.1073/pnas.96.22.12536

55. Kvansakul M, van Delft MF, Lee EF, Gulbis JM, Fairlie WD, Huang DC, et al. A structural viral mimic of prosurvival Bcl-2: a pivotal role for sequestering proapoptotic Bax and Bak. Mol Cell (2007) 25(6):933-42. doi: 10.1016/ j.molcel.2007.02.004

56. Tarodi B, Subramanian T, Chinnadurai G. Epstein-Barr virus BHRF1 protein protects against cell death induced by DNA-damaging agents and heterologous viral infection. Virology (1994) 201(2):404-7. doi: 10.1006/ viro.1994.1309

57. Barrera-Vázquez OS, Cancio-Lonches C, Hernández-González O, ChávezMunguia B, Villegas-Sepúlveda N, Gutiérrez-Escolano AL. The feline calicivirus leader of the capsid protein causes survivin and XIAP downregulation and apoptosis. Virology (2019) 527:146-58. doi: 10.1016/j.virol.2018.11.017

58. Garant KA, Shmulevitz M, Pan L, Daigle RM, Ahn DG, Gujar SA, et al. Oncolytic reovirus induces intracellular redistribution of Ras to promote apoptosis and progeny virus release. Oncogene (2016) 35(6):771-82. doi: 10.1038/onc.2015.136

59. Yuan S, Zhang N, Xu L, Zhou L, Ge X, Guo X, et al. Induction of apoptosis by the nonstructural protein 4 and 10 of porcine reproductive and respiratory syndrome virus. PloS One (2016) 11(6):e0156518. doi: 10.1371/journal.pone.0156518

60. Flegel TW. Update on viral accommodation, a model for host-viral interaction in shrimp and other arthropods. Dev Comp Immunol (2007) 31:217-31. doi: 10.1016/j.dci.2006.06.009

61. Yan F, Xia D, lv S, Qi Y, Xu H. Functional analysis of the orf390 gene of the White Spot Syndrome Virus. Virus Res (2010) 151:39-44. doi: 10.1016/ j.virusres.2010.03.014

62. Leu JH, Chen LL, Lin YR, Kou GH, Lo CF. Molecular mechanism of the interactions between white spot syndrome virus anti-apoptosis protein AAP-1 (WSSV449) and shrimp effector caspase. Dev Comp Immunol (2010) 34:106874. doi: 10.1016/j.dci.2010.05.010

63. Wang HC, Ko TP, Lee YM, Leu JH, Ho CH, Huang WP, et al. White spot syndrome virus protein ICP11: A histone-binding DNA mimic that disrupts nucleosome assembly. Proc Natl Acad Sci U States America (2008) 105:2075863. doi: $10.1073 /$ pnas. 0811233106

64. Wang PH, Huang T, Zhang X, He JG. Antiviral defense in shrimp: From innate immunity to viral infection. Antiviral Res (2014) 108:129-41. doi: 10.1016/j.antiviral.2014.05.013

65. Sun YM, Li FH, Xiang JH. Analysis on the dynamic changes of the amount of WSSV in Chinese shrimp Fenneropenaeus chinensis during infection. Aquaculture (2013) 376:124-32. doi: 10.1016/j.aquaculture.2012.11.014

66. Li C, Weng S, He JG. WSSV-host interaction: Host response and immune evasion. Fish Shellfish Immunol (2018) 84:558-71. doi: 10.1016/j.fsi.2018.10.043

67. Roulston A, Marcellus RC, Branton PE. Viruses and Apoptosis. J Gen Virol (1999) 53:577-628. doi: 10.1146/annurev.micro.53.1.577
68. Wu JL, Muroga K. Apoptosis does not play an important role in the resistance of 'immune' Penaeus japonicus against white spot syndrom virus. J Fish Dis (2004) 27:15-21. doi: 10.1046/j.1365-2761.2003.00491.x

69. Badley AD, Pilon AA, Landay A, Lynch DH. Mechanisms of HIV-associated lymphocyte apoptosis. Blood (2000) 96:2951-64. doi: 10.1182/ blood.V96.9.2951.h8002951_2951_2964

70. Ahr B, Robert-Hebmann V, Devaux C, Biard-Piechaczyk M. Apoptosis of uninfected cells induced by HIV envelope glycoproteins. Retrovirology (2004) 1:12. doi: $10.1186 / 1742-4690-1-12$

71. Okada H, Kobune F, Sato TA, Kohama T, Takeuchi Y, Abe T, et al. Extensive lymphopenia due to apoptosis of uninfected lymphocytes in acute measles patients. Arch Virol (2000) 145:905-20. doi: 10.1007/s007050050683

72. Bosnjak L, Miranda-Saksena M, Koelle DM, Boadle RA, Jones CA, Cunningham AL. Herpes Simplex Virus Infection of Human Dendritic Cells Induces Apoptosis and Allows Cross-Presentation via Uninfected Dendritic Cells. J Immunol (2005) 174:2220-7. doi: 10.4049/jimmunol.174.4.2220

73. Linda D, Pedro SC, Inmaculada G, Covadonga A. Investigations of Pro- and Anti-Apoptotic Factors Affecting African Swine Fever Virus Replication and Pathogenesis. Viruses (2017) 9:241. doi: 10.3390/v9090241

74. Li M, Li J, Yang J, Liu J, Zhang Z, Song X, et al. RSV replication is promoted by autophagy-mediated inhibition of apoptosis. J Virol (2018) 92:02193. doi: 10.1128/JVI.02193-17

75. Li F, Chang X, Xu L, Yang F. Different roles of crayfish hemocytes in the uptake of foreign particles. Fish Shellfish Immunol (2018) 77:112-9. doi: 10.1016/j.fsi.2018.03.029

76. Du J, Zhu H, Ren Q, Liu P, Chen J, Xiu Y, et al. Flow cytometry studies on the Macrobrachium rosenbergii hemocytes sub-populations and immune responses to novel pathogen spiroplasma MR-1008. Fish Shellfish Immunol (2012) 33:795-800. doi: 10.1016/j.fsi.2012.07.006

77. Xian JA, Zhang XX, Wang DM, Li JT, Zheng PH, Lu YP. Various cellular responses of different shrimp haemocyte subpopulations to lipopolysaccharide stimulation. Fish Shellfish Immunol (2017) 69:195-9. doi: $10.1016 /$ j.fsi.2017.08.025

78. Havanapan PO, Taengchaiyaphum S, Ketterman AJ, Krittanai C. Yellow head virus infection in black tiger shrimp reveals specific interaction with granulecontaining hemocytes and crustinPml as a responsive protein. Dev Comp Immunol (2016) 54:126-36. doi: 10.1016/j.dci.2015.09.005

79. Liu CH, Cheng W, Chen JC. The peroxinectin of white shrimp Litopenaeus vannamei is synthesised in the semi-granular and granular cells, and its transcription is up-regulated with Vibrio alginolyticus infection. Fish Shellfish Immunol (2005) 18:431-44. doi: 10.1016/j.fsi.2004.10.005

80. Ding ZF, Du J, Ou JT, Li WJ, Wu T, Xiu YJ, et al. Classification of circulating hemocytes from the red swamp crayfish Procambarus clarkii and their susceptibility to the novel pathogen Spiroplasma eriocheiris in vitro. Aquaculture (2012) 356:371-80. doi: 10.1016/j.aquaculture.2012.04.042

Conflict of Interest: The authors declare that the research was conducted in the absence of any commercial or financial relationships that could be construed as a potential conflict of interest.

Copyright () 2020 Cui, Liang, Tang, Xing, Sheng and Zhan. This is an open-access article distributed under the terms of the Creative Commons Attribution License (CC BY). The use, distribution or reproduction in other forums is permitted, provided the original author(s) and the copyright owner(s) are credited and that the original publication in this journal is cited, in accordance with accepted academic practice. No use, distribution or reproduction is permitted which does not comply with these terms. 